\title{
Poetamenos, de Augusto de Campos: UMA TRANSCRIAÇÃO INTERSEMIÓTICA DA KLANGFARBENMELODIE, DE ANTON VON WEBERN
}

\author{
Poetamenos by Augusto de Campos: an \\ INTERSEMIOTIC TRANSCREATION OF ANTON \\ VON WeBERN'S KLANGFARBENMELODIE
}

João Queiroz ${ }^{1}$

ORCID 0000-0001-6978-4446

Ana Luiza Fernandes ${ }^{2, *}$

ORCID 0000-0003-3598-2916

\section{Marta Castello Branco ${ }^{1}$ \\ ORCID 0000-0002-2926-0215}

${ }^{1}$ Universidade Federal de Juiz de Fora Juiz de Fora, MG, Brasil

${ }^{2}$ Pontifícia Universidade Católica do Rio de Janeiro Rio de Janeiro, RJ, Brasil

\section{Resumo}

Poetamenos, o principal precursor do concretismo no Brasil, é uma transcriação intersemiótica da Klangfarbenmelodie, de Anton Webern. Trata-se de uma série de seis poemas, elaborados por Augusto de Campos entre 1952 e 1953. A transcriaçáo da técnica serial musical está relacionada ao fim do ciclo histórico do verso e fornece à "linha evolutiva" preconizada pelos concretistas um modelo e um método criativo rigorosos. Em nossa argumentação, Poetamenos revela: (i) uma compreensão dialética da tensão som-silêncio através da fragmentação, dispersão e acúmulo de letras, sílabas e estruturas lexicais; (ii) o rigor formal e metodológico elaborado por Webern; (iii) os efeitos do serialismo weberniano nos anos 1950, cuja entrada no Brasil deve-se a Hans-Joachim Koellreutter. Também concluímos que o uso de procedimentos gráfico-espaciais, plurilíngues e policromáticos, no Poetamenos,

\footnotetext{
* Ana Luiza Fernandes agradece ao Conselho Nacional de Desenvolvimento Científico e Tecnológico $(\mathrm{CNPq})$ o apoio recebido por meio de bolsa de doutorado. O presente trabalho foi realizado com apoio da Coordenação de Aperfeiçoamento de Pessoal de Nível Superior - Brasil (CAPES) - Código de Financiamento 001.
} 
não possui uma precisa correspondência com componentes composicionais do serialismo, nem com qualquer das obras de Webern, em particular, como muitos autores defendem.

Palavras-chave: Poetamenos; Augusto de Campos; Anton Webern; Klangfarbenmelodie; transcriação intersemiótica.

\section{Abstract}

Poetamenos, the main precursor of concretism in Brazil, is an intersemiotic transcreation of Anton Webern's Klangfarbenmelodie. It is a series of six poems written by Augusto de Campos between 1952 and 1953 . The transcreation of the serial music technique is related to the end of the historical cycle of the verse and provides a rigorous and creative method to the "evolutionary line" indicated by the concretists. According to our arguments, Poetamenos reveals (i) a dialectical understanding of the sound-silence tension through the fragmentation, dispersion and accumulation of letters, syllables, and lexical structures; (ii) the formal and methodological rigor developed by Webern; (iii) the effects of Webernian serialism in the 1950s, which entered Brazil thanks to Hans-Joachim Koellreutter. We also conclude that the use of graphic-spatial, plurilingual and polychromatic procedures does not have a precise correspondence with compositional components of serialism, nor with any of Webern's works in particular, as many authors claim.

Keywords: Poetamenos; Augusto de Campos; Anton Webern; Klangfarbenmelodie; intersemiotic transcreation.

\section{Resumen}

Poetamenos, el principal precursor del concretismo en Brasil, es una transcreación intersemiótica del Klangfarbenmelodie de Anton Webern. Se trata de una serie de seis poemas, escritos por Augusto de Campos entre 1952 y 1953. La transcreación de la técnica de la musica serial se relaciona con el final del ciclo histórico del verso y proporciona la "línea evolutiva" recomendada por los concretistas con un modelo y un método estrictamente creativo. En nuestro argumento, Poetamenos revela: (i) una comprensión dialéctica de la tensión sonido-silencio a través de la fragmentación, dispersión y acumulación de letras, sílabas y estructuras léxicas; (ii) el rigor formal y metodológico elaborado por Webern; (iii) los efectos del serialismo weberniano en la década de 1950, cuya entrada en Brasil se debió a Hans-Joachim Koellreutter. También concluimos que el uso de procedimientos gráfico-espaciales, multilingües y policromáticos en Poetamenos no tiene una correspondencia precisa con los componentes compositivos del serialismo, ni con ninguna de las obras de Webern, en particular, como defienden muchos autores.

Palabras clave: Poetamenos; Augusto de Campos; Anton Webern; Klangfarbenmelodie; transcreación intersemiótica. 
A série de poemas Poetamenos, de Augusto de Campos, a principal precursora da poesia concreta no Brasil, é uma tradução intersemiótica, ou transcriação, do serialismo de Anton Webern. ${ }^{1}$ Escrita entre 1952 e 1953, a série de seis poemas ("poetamenos", "paraíso pudendo", "lygia fingers", "nossos dias com cimento", "eis os amantes" e "dias dias dias") foi publicada em 1955, na segunda edição da revista Noigandres. Antes da publicação na Noigandres 2, os poemas foram impressos artesanalmente, em pequena tiragem, em carbonos coloridos. Em 1954, Augusto de Campos chegou a inscrever a série no Concurso da Biblioteca Mário de Andrade, sem êxito. No mesmo ano, Décio Pignatari, em parceria com Vinholes, Damiano Cozzella e outros, promoveram a leitura de alguns dos poemas no V Curso Internacional de Férias, em Teresópolis. Em 1955, no Teatro Arena, em São Paulo, em gravação analógica integrada à projeção de diapositivos, o grupo Ars Nova interpretou os poemas "lygia fingers", "eis os amantes" e "nossos dias com cimento", sob a regência do maestro Diogo Pacheco e supervisão de Augusto de Campos, acompanhados pela música de Webern. O evento, estreado no dia 21 de novembro de 1955, foi noticiado no jornal O Estado de São Paulo com o título Música e Poesia Concretas. Como informa Augusto, "em sincronizaçáo com a terminologia adotada pelas artes visuais e, até certo ponto, pela música de vanguarda, diria eu que há uma poesia concreta" (CAMPOS, 2015, p. 87).

Poetamenos, além dos protocolos experimentais de construçáo e apresentação visuais, também inaugura novos padróes de oralização - "na leitura oral, Poetamenos foi a proposta que chegou mais longe, ao propor uma leitura a várias vozes e 'cores' e com cortes abruptos e dissonâncias que escapavam a toda preceptiva poética” (AGUILAR, 2005, p. 182). ${ }^{2}$ Contra "as críticas centradas na impossibilidade de oralização dos textos, os poetas responderam com um portmanteau joyceano: a poesia é verbivocovisual" (AGUILAR, 2005, p. 288). Três poemas da série foram reimpressos na antologia Noigandres 5, de 1962. Em 1979, a série completa foi novamente publicada na antologia Viva Vaia, de Augusto de Campos.

A série está, intersemioticamente, através do serialismo de Webern, relacionada ao "fim do ciclo histórico do verso" e ao resultado de uma "linha

1 Haroldo de Campos fez uso de diferentes termos para designar a prática criativa de "tradução interlinguística", atento à "materialidade", ou à "fisicalidade", do signo traduzido: transcriação (CAMPOS, 1972, p. 109; 1986, p. 7), transposição criativa (CAMPOS, 1972, p. 110), reimaginação (CAMPOS, 1972, p. 121), são alguns dos termos usados por Haroldo. Nossa opção pelo uso do termo "transcriação" está, portanto, em diálogo direto com a definição de Haroldo.

2 Para ver os tratamentos sonoro-musicais dedicados ao Poetamenos: "lygia fingers", por Augusto de Campos: https://www.youtube.com/watch?v=wx0XqXpQtO8; "dias dias dias", por Caetano Veloso: https://youtu.be/MpXwgmMQu5c; "lygia fingers", de Daniel Duarte Loza. Intérpretes (vozes): Andrés Duarte Loza, Silvina Spinardi, Laur Villasol, Daniel Duarte Loza (2004). Buenos Aires. Animação digital: Augusto de Campos: https://www.youtube.com/watch?v=Zy74PDQC7zc 
evolutiva formal" preconizada pelos concretistas (AGUILAR, 2005, p. 180). É claro que também está associada aos desenvolvimentos da escola Escola de Ulm, aos experimentos de Max Bill, e do neoplasticismo de Mondrian (AGUILAR, 2005, p. 167). Mas há, na relação com o serialismo de Webern, um componente adicional que Aguilar chama de "fetiche da técnica", mais "orgânica" no caso da música - os ensaios concretistas "estáo sempre organizados em torno de uma revisão das técnicas e procedimentos" (AGUILAR, 2005, p. 180). Poetamenos também pode ser descrito como um ícone do uso das cores-timbres, que corresponde ao uso do timbre que Adorno relaciona à obra de Webern, da mudança de timbres na sequência melódica, fragmentando a melodia.

Investigamos as relações entre a "melodia de timbres" e a música serial de Webern, destacando a concisão e a síntese do material musical, a técnica que cria coesão formal frente à fragmentação melódica, rítmica e harmônica. Em nossa argumentação, o uso de procedimentos gráfico-espaciais, plurilíngues e policromáticos do Poetamenos não possui direta correspondência com componentes composicionais do serialismo de Webern, nem com qualquer uma de suas obras em particular, como muitos autores defendem. Como uma transcriação do signo-fonte, Poetamenos revela: (i) uma compreensão dialética da tensão som-silêncio através da fragmentação, dispersão e acúmulo de letras e estruturas lexicais; (ii) o rigor formal-metodológico elaborado por Webern para obter síntese e concisão através da fragmentação; (iii) os efeitos ou implicaçóes do serialismo weberniano, nos anos 1950, no Brasil, cuja entrada acontece por meio de Hans-Joachim Koellreutter.

\section{Augusto de Campos: Poetamenos}

Poetamenos é uma série de seis poemas ("poetamenos", "paraíso pudendo", "lygia fingers", "nossos dias com cimento", "eis os amantes" e "dias dias dias") e um texto introdutório (Figura 1) em que Augusto de Campos esboça as premissas de seu experimento.

O verso, como unidade rítmica, formal e ideológica (AGUILAR, 2005, p. 176), e a sintaxe discursiva, são abandonados no Poetamenos, e as palavras, impressas em diferentes cores, criam complexas estruturas gráficoespaciais. Trata-se de uma antecipação daquilo que vai se consolidar no que é chamado "fase ideogramática" da poesia concreta (AGUILAR, 2005, p. 184). Como as estruturas gráfico-espaciais, plurilíngues e policromáticas, do Poetamentos, transcriam procedimentos seriais webernianos? Para Aguilar (2005, p. 291), "o valor das cores é autônomo e estrutural: o sentido de cada uma está na combinação que estabelece com as outras cores do poema (contraste, parentesco, vibração, gradação)". Em nossa análise musical dos poemas, a função estrutural das cores nos parece mais estreitamente associada a outros elementos estruturais - tipográfico, gráfico, fonético, semântico. 
ou aspirando à esperança de uma

\author{
KLANGFARBENMELODIE \\ (melodiadetimbres)
}

com palavras

como em WEBERN:

uma melodia contínua deslocada de um instrumento para outro, mudando constantemente sua cor:

instrumentos: frase/palavra/silaba/letra(s), cujos timbres se definam p/ um tema gráfico-fonético ou "ideogrâmico".

$\therefore$ a necessidade da representação gráfica em cores (q ainda assim apenas aproximadamente representam, podendo diminuir em funcionalidade em ctos casos complexos de superposição e interpenetração temática), excluída a representação monocolor q está para o poema como uma fotografia para a realidade cromática.

mas luminosos, ou filmletras, quem os tivera!

reverberação: leitura oral - vozes reais agindo em (aproximadamente) timbre para o poema como os instrumentos na klangfarbenmelodie de WEBERN.

Figura 1 - Introdução ao Poetamenos. 
Divergimos, como veremos, da tese que afirma que, no Poetamenos, para cada voz/instrumento existe uma cor correspondente e que o silêncio é representado pelos espaços em branco (ver BESSA, 2009; CARVALHO, 2007; AGUILAR, 2005).

A pontuação não-ortodoxa também atua como procedimento estrutural (CAMARA, 2000, p. 84-85). O plurilinguismo é outra importante propriedade. Há palavras em português, alemão, latim, italiano, inglês, francês e espanhol. "lygia fingers" (Figura 2), escrito em inglês, italiano, alemão e latim, é formado por cinco cores, três primárias (vermelho, amarelo, azul) e duas secundárias (verde e violeta). Há paralelismos entre finge e fingers (dedos), e lynx (do inglês lince), que pode ser lido como links (ligaçôes). Em alemáo, lynx (links) significa esquerda (lynx aparece duas vezes alinhada à esquerda). Outra expressão, so lange so (significando: há tanto tempo) remete a Solange Sohl, ${ }^{3}$ do poema "O Sol por Natural". A palavra italiana gia (já) liga-se a ly formando o nome Lygia, distribuído pelo poema, impresso em vermelho. Lygia, que é a mulher, é também a figlia (filha) e a sorella (irmã).

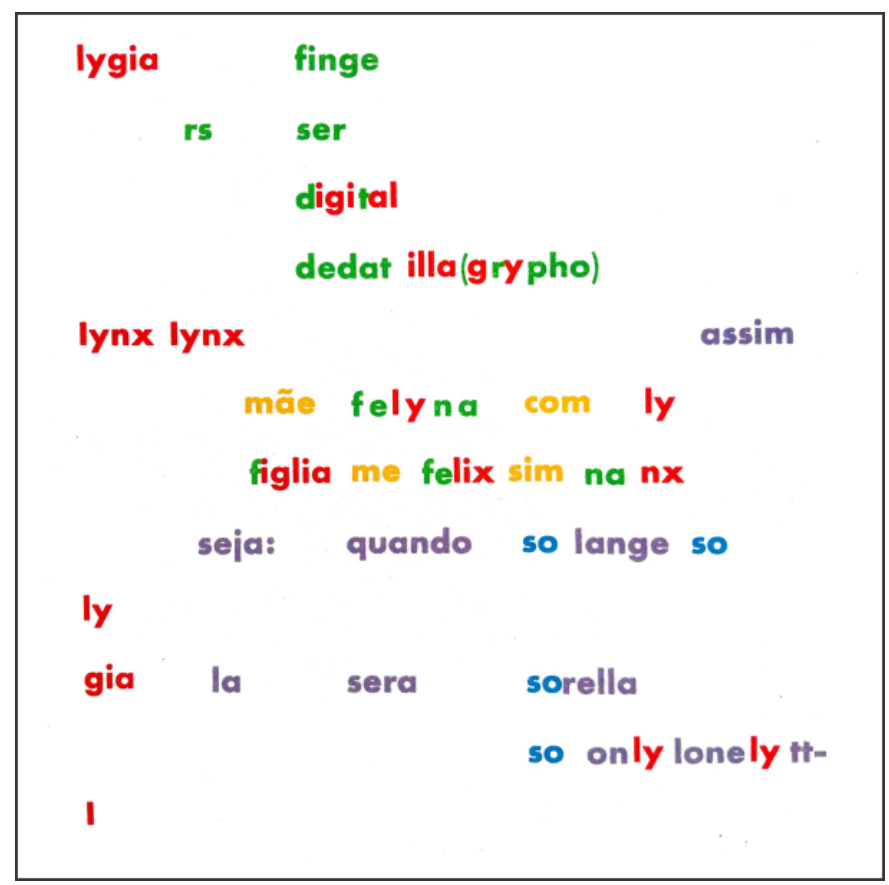

Figura 2 - "lygia fingers".

3 Solange Sohl é pseudônimo de Patrícia Galvão, ou Pagu, escritora modernista, poeta, dramaturga, tradutora, desenhista, cartunista, jornalista e militante comunista. Sobre a escritora, Augusto escreveu, anos depois, uma longa biografia (CAMPOS, 2014). 
Em "dias dias dias" (Figura 3), para Carvalho (2007, p. 35), "há duas referências em 'dias dias dias': 'os dias na esperança de um só dia', de Camóes, em 'Sete Anos de Pastor', e 'Oh! se me lembro! e quanto!', do sonetista parnasiano Luís Guimarães Júnior (1847-1898)”. Segundo Aguilar (2005, p. 296), o poema originou-se de "uma carta que Augusto de Campos enviou à sua então namorada Lygia Azeredo (posteriormente, sua esposa), em 20 de julho de 1953 (a carta-poema, nesta primeira versão não-colorida, foi escrita nos dias 18 e 19 daquele mês)".

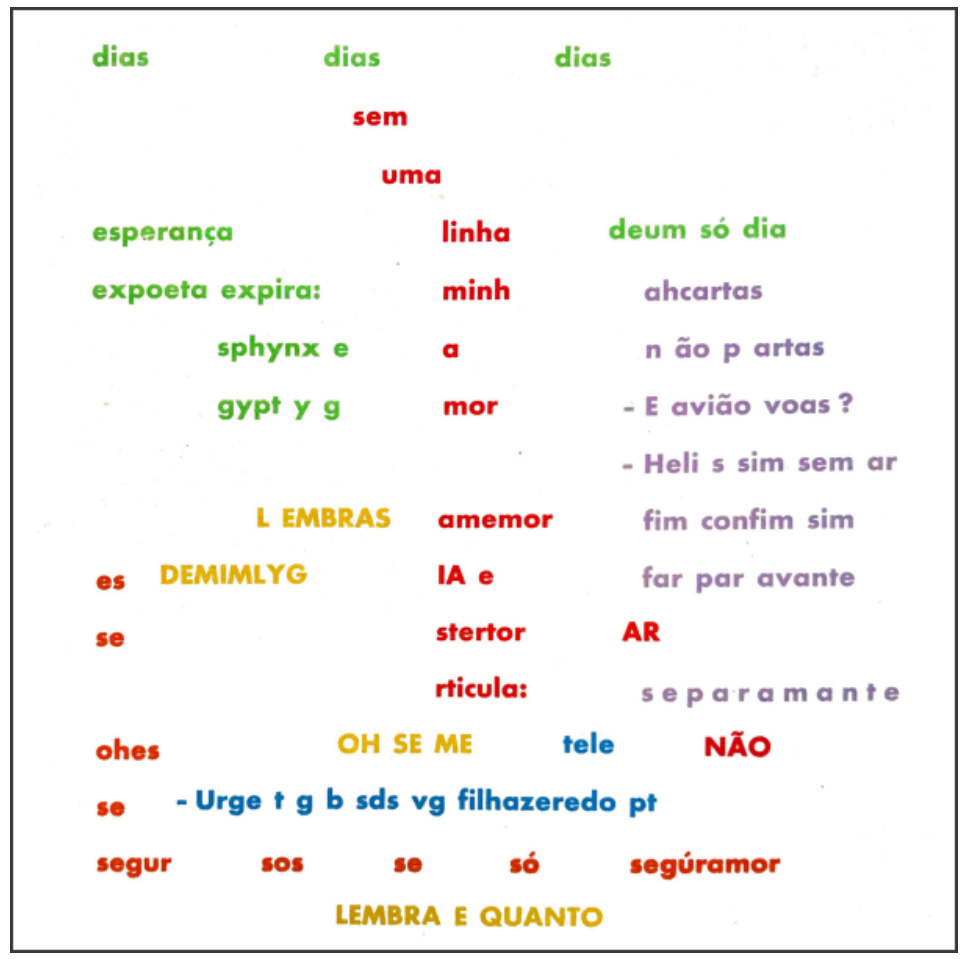

Figura 3 - "dias dias dias".

De volta à nossa questão: como os poemas traduzem a Klangfarbenmelodie? Além da referência à obra de Webern, a literatura secundária afirma que há uma relação direta entre as cores usadas e a "melodia de timbres". Discordamos. Uma investigação musicológica do termo, e sua utilização composicional, são necessárias para uma análise da transcriação de Webern.

Anton Webern: Klangfarbenmelodie

A proposta do termo Klangfarbenmelodie é do compositor Arnold Schoenberg, e aparece no final de seu Tratado de Harmonia (Harmonielehre), 
de 1911. Schoenberg sugere a criação de uma "estrutura de timbres", já que outros parâmetros sonoros, especialmente a altura, foram muito mais investigados.

Três qualidades são reconhecidas no som: sua altura, timbre e intensidade. Até o presente momento, o som tem sido medido somente em uma das três dimensôes nas quais se projeta; naquela que denominamos altura. Tentativas de se medir as outras dimensões praticamente não foram feitas e a ordenação de seus resultados em um sistema, simplesmente inexiste. Assim, a valorizaçáo do timbre, a segunda dimensão do som, se encontra em um estado ainda mais desconstruído e desordenado do que a valorização estética das harmonias nomeadas anteriormente (SCHOENBERG, 1922, p. 506, tradução nossa) $)^{4}$.

Em seu verbete, "melodia de timbres", ou Klangfarbenmelodie, escrito para a obra de Hans Heinrich Eggebrecht (1995), e dedicada à terminologia da música do século XX, Rainer Schmusch (1995, p. 222) é enfático sobre uma sistematização do timbre para concepção de uma "melodia de timbres". Ele também é enfático sobre a necessidade de uma lógica musical da sequência timbrística, relacionada à ideia de melodia, ainda que expandida. No entanto, a apresentação do termo "melodia de timbres", por Schoenberg, deixa evidente que tais condiçóes não existiam em sua própria obra. Muito antes, o próprio Schoenberg (1922, p. 507, tradução nossa) apresenta a ideia como uma "fantasia do futuro":

Isso parece uma fantasia do futuro e provavelmente o é. Mas trata-se de uma fantasia que eu realmente acredito que se realizará. [...] Melodia de timbres! Que fineza de sentidos a reconhecerá, que mente altamente desenvolvida encontrará diversão em coisas tão sutis! ${ }^{5}$

Para Schmusch (1995, p. 222, tradução nossa), “a ambiguidade é característica da apresentação de Schoenberg [da melodia de timbres]: permanece não esclarecido se ela significa o timbre do espectro sonoro de cada

4 "Am Klang werden drei Eigenschaften erkannt: seine Höhe, Farbe und Stärke. Gemessen wurde er bisher nur in einer der drei Dimensionen, in denen er sich ausdehnt. In der, die wir Tonhöhe nennen. Messungsversuche in den anderen Dimensionen wurden bisher kaum unternommen, ihre Ergebnisse in ein System zu ordnen, noch gar nicht versucht. Die Bewertung der Klangfarbe, der zweiten Dimension des Tons, befindet sich also in einem noch viel unbebautern, ungeordnetern Zustand als die ästhetische Wertung dieser letztgenannten Harmonien" (SCHOENBERG, 1922, p. 506). Schoenberg se refere especificamente à harmonia de acordes formados por seis ou mais sons (Todas as traduçôes são dos autores deste trabalho, exceto quando indicado de outra maneira.)

5 "Das scheint eine Zukunftsphantasie und ist es wahrscheinlich auch. Aber eine, von der ich fest glaube, dass sie sich verwirklichen wird. [...] Klangfarbenmelodie! Welche feinen Sinne, die hier unterscheiden, welcher hochentwickelte Geist, der an so subtilen Dingen Vergnügen finden mag!" (SCHOENBERG, 1922, p. 507). 
instrumento musical ou se é a mistura de timbres que precisa ser sistematizada por uma composição orquestral". ${ }^{6} \mathrm{Na}$ década de 1920, o termo "melodia de timbres" passa a ser utilizado por autores do círculo de Schoenberg e se torna um termo corrente em análise musical. Nesse momento, Schmusch identifica dois sentidos distintos relacionados ao termo, resultado de várias apropriaçóes, por diversos autores: "No correr dos anos 1920, o termo 'melodia de timbres' é transformado em um termo de análise musical pelos autores do círculo de Schoenberg: (a) tendo como sentido principal a mudança de timbres de alturas idênticas e (b) o sentido secundário de mudança de timbres em sequência melódica” (SCHMUSCH, 1995, p. 221; tradução nossa, ênfases do autor). ${ }^{7}$

Do mesmo círculo de autores que se estabeleceu ao redor de Schoenberg, surge a relação entre o termo "melodia de timbres" e a obra de Webern. Mas, como no caso de Schoenberg, o termo não é apresentado clara e tecnicamente. Foi Theodor Adorno (1926) quem afirmou que Webern teria realizado a ideia de uma "melodia de timbres". 8 Também Alban Berg utiliza o termo, com relação à obra de Webern. Ele afirma que, nas Seis Bagatelas para Quarteto de Cordas, Op. 9, cada nota de uma melodia possui um novo timbre, através do uso de flageolett, pizzicato, col legno etc. Assim como Webern, Alban Berg foi aluno de Schoenberg e se dedicou à técnica dodecafônica e às suas potencialidades musicais. Sua compreensão do termo "timbre" é bastante literal. Berg considera técnicas específicas dos instrumentos de corda como diferentes timbres - flageolett, pizzicato, col legno modificam suas sonoridades usuais. Neste caso, o termo "melodia de timbres" é usado para designar uma mudança de timbres em uma sequência melódica. Segundo Schmusch (1995, p. 227), isso foi afirmado pelo próprio compositor sobre sua orquestração para o Ricercare da Oferenda Musical, de Bach. Adorno concorda sobre o fato de que a "melodia de timbres" na obra de Webern está relacionada à mudança de timbres em uma sequência melódica. Mas Schmusch destaca uma diferença entre Webern e Schoenberg - a fragmentação da melodia é uma característica de Webern, enquanto para Schoenberg e Alban Berg a modificação do timbre preserva a função de formar melodias (SCHMUSCH, 1995, p. 227-228). Adorno é enfático sobre a diferença entre fragmentação

6 "Charakteristisch für Schönbergs Darstellung ist ihre Uneindeutigkeit: Ob mit Klangfarbe das Obertonspektrum des jeweils einzelnen Musikinstr. gemeint ist, oder ob es sich dabei um die komponierte orchestrale Mischklangfarbe handelt, die systematisiert werden soll, bleibt unklar" (SCHMUSCH, 1995, p. 222).

7 "Im Laufe der 1920er Jahre wird Klangfarbenmelodie von Autores des Schoenbergkreises zum terminus der musikanalyse erhoben mit (a) der Hauptbedeutung klangfarben wechsel identicher klánge und (b) der Nebenbedeutung klangfarben wechsel melodischer tonfolgen" (SCHMUSCH, 1995, p. 221). Os grifos são do próprio autor, Rainer Schmusch.

8 “Die Idee der Klangfarbenmelodie hat Webern realisiert” (ADORNO, 1926). 
e coesão melódicas. Apenas Webern representa o primeiro caso, em oposição a Schoenberg e Berg que, segundo o musicólogo, usam a modificação de timbres sem alterar a formação de melodias.

Schoenberg nunca restringiu o significado de "melodia de timbres" à troca de timbres de alturas idênticas, nem à sequência melódica. Em seu livro Estilo e Ideia, o compositor afirma que se tratava mais de um problema não resolvido da forma composicional.

É preciso que esteja especialmente claro para todos, que eu pensei em sequências de timbres que correspondem à lógica interna de sequências harmônicas. As chamei de melodias, porque elas precisam ser formadas assim como melodias, ainda que de acordo com leis correspondentes à sua própria natureza (SCHOENBERG, 1975, p. 483, tradução nossa). ${ }^{9}$

Schoenberg afirma que Webern lhe apresentou uma peça e questionou-o sobre sua forma, se ela poderia ser reconhecida como uma canção em três seções, devido à "melodia de timbres" (SCHOENBERG, 1975, p. 483). Tal observação pareceu ingênua a Schoenberg, que afirmou que melodias de timbres precisam ter uma organização especial, mesmo que indiquem certa semelhança com outras formas musicais. Mas elas precisam satisfazer exigências de um novo fator, com novas consequências (SCHOENBERG, 1975, p. 483). ${ }^{10}$ É bastante provável que a forma canção, em três seções, se deva à sua sequência harmônica, a seu desenvolvimento temático, ou a qualquer outro fator estruturador formal, e não à "melodia de timbres".

No texto introdutório ao Poetamenos (Figura 1), Augusto de Campos estabelece uma relação direta com a melodia de timbres de Webern, e escolhe o termo Klangfarbenmelodie para representar sua "esperança por uma melodia de timbres" com palavras. Klangfarbenmelodie parece se referir a uma técnica, mesmo não se constituindo independentemente como tal, nem na obra de Schoenberg, nem de Webern, nem posteriormente. As propostas composicionais de uma Klangfarbenmelodie se relacionam diretamente com outra técnica - serial ou serialismo. Sempre que uma série contiver todos os doze sons que compóem uma escala cromática, ela é denominada dodecafônica. No domínio da música serial, há uma enorme discussão musicológica sobre qual deveria ser o emprego da Klangfarbenmelodie em diferentes obras, de

9 "Aber insbesondere müsste es jedem klar sein, dass ich an Folgen von Klangfarben gedacht habe, die der innern Logik von Harmoniefolgen gleichkommen. Melodie habe ich genannt, weil sie im selben Maße geformt sein müssten, wie Melodien, jedoch nach eigenen, ihrer Natur entsprechenden Gesetzen" (SCHOENBERG, 1975, p. 483).

10 Segundo Rainer Schmusch, as composições de Webern em três seçôes eram os Orchesterstücke Op. 6 (1995, p. 229). 
distintos compositores, e em diversos períodos históricos. Após a sugestão do termo "melodia de timbres", por Schoenberg, algumas atribuiçốes sobre sua utilização foram feitas, sobretudo por musicólogos. A imprecisão entre o termo e sua sistematização como técnica composicional independente é uma característica de tais atribuiçôes. $\mathrm{O}$ termo apresenta imprecisóes, tanto musicais, quanto musicológicas e históricas. No caso do Poetamenos, soma-se à dificuldade em se compreender a Klangfarbenmelodie como uma técnica, as traduçóes culturais sofridas pela música serial na América Latina, como veremos.

Mas se consideramos a Klangfarbenmelodie uma técnica composicional, no contexto serial, podemos encontrar um paralelo entre o uso do timbre por Webern e por Augusto de Campos. Poetamenos revela um uso das corestimbres que corresponde ao uso do timbre que Adorno relaciona à obra de Webern. Trata-se da ideia de uma mudança de timbres na sequência melódica, que fragmenta a melodia. Augusto apresenta essa ideia, de uma sequência melódica, logo na introdução à série (Figura 1): "uma melodia contínua deslocada de um instrumento para outro, mudando constantemente sua cor". A operação indica uma sucessão melódica, não uma repetição de alturas. Notem que uma mudança de timbre em alturas idênticas não é explorada no Poetamenos, em letras, sílabas ou estruturas lexicais. O caso mais exemplar é o poema "lygia fingers" (ver Figura 2), onde a sílaba ly se repete várias vezes, sempre com a mesma cor vermelha. Em "dias, dias, dias" (ver Figura 3), a repetição da palavra é sempre colorida em verde. Já a mudança de timbre em uma sequência melódica é frequente, e a fragmentação de estruturas vocabulares, como a quebra da melodia de Webern, descrita por Adorno, é mais facilmente observada. Mas, para isso, duas outras correspondências entre música e poesia devem ser consideradas. Em primeiro lugar, para que a descrição de Adorno possa corresponder ao que observamos no poema, a melodia musical deve estar supostamente relacionada à sentença verbal, e à certa unidade semântica, como uma estrutura fragmentada. Em segundo lugar, o timbre (musical) deve estar relacionado à cor no poema — da palavra "Farbe" (cor), em Klangfarbenmelodie —, embora os termos que se aglutinam sejam Klangfarben (timbres) e Melodie (melodia), e não "cores do som", Klang e Farben. Este último sentido tem sido largamente relacionado à série Poetamenos pela literatura secundária.

Segundo Aguilar (2005, p. 291), a mudança de cor nos poemas da série possui uma função estruturadora. ${ }^{11}$ Clüver também enfatiza, além da

11 O termo "estrutura" recebe um tratamento muito técnico (baseado na Gestalt) pelos concretos (ver Plano Piloto Poesia Concreta). Ele também é tratado tecnicamente por muitos compositores. Segundo Boulez (apud AGUILAR, 2005, p. 191): "Quando eu mesmo ministrei cursos de análise, já não me interessava uma análise nota por nota. Buscava a análise por uma forma global, por Gestalt; tomava as 
mudança de cores, o uso de letras capitais e espacialização (CLÜVER, 1981, p. 387). Há grupos de duas a seis cores para cada poema, às quais se somam cores "intrusas", que vêm de "movimentos-poemas" anteriores e atuam na construção de uma estrutura coesa e dinâmica. A alteração de cores não é determinada por letras, sílabas ou vocábulos, fenômeno de uma "melodia de timbre" baseada na repetição de alturas.

É um argumento bem conhecido que a representaçáo gráfica define, no concretismo, uma nova sintaxe. A investigação de funções estruturais da "melodia de timbres", que parecia ao Schoenberg uma possibilidade futura, pode ser lida no Poetamenos, sobretudo no uso dos diversos códigos semânticos e na espacialização gráfica. Ainda que a relação entre timbre e cor tenha sido bastante explorada na literatura sobre o Poetamenos, não são apenas as cores que representam uma transcriação da "melodia de timbres". O uso das cores que transcria, musicalmente, uma orquestração (instrumentação) dos poemas, parece bem claro na introdução à série (ver Figura 1) (1953), quando o timbre é relacionado não apenas às cores, mas a temas gráfico-fonéticos: "instrumentos: frase / palavra / sílaba / letra (s), cujos timbres se definam p/ um tema gráficofonético ou ideogrâmico" (ver Figura 1). Mais detalhadamente, não apenas as cores estão relacionadas aos timbres - estruturas espaciais e vocabulares, que também são definidas por cores, criam estruturas gráfico-fonéticas.

Se os poemas também foram concebidos para oralização (ver AGUILAR; CÁMARA, 2017), e Augusto de Campos considera a "reverberação" da "leitura oral" de "vozes reais funcionando como timbre", este é mais um elemento de contato com Schoenberg — a relação entre timbre e altura. Vozes distintas têm timbres naturalmente distintos e variam em faixas de alturas que respeitam as articulaçóes de cada sílaba ou de cada vocábulo. Para Schoenberg, não se pode indicar exatamente a diferença entre timbre e altura, como é usualmente apresentado, pois a altura é uma parte integrante do timbre e "é possível deixar com que surjam formas que denominamos melodias, a partir de timbres que se diferenciam por alturas" (SCHOENBERG, 1922, p. 506, tradução nossa). ${ }^{12}$ Mas a escolha de Augusto por Webern certamente não resulta de uma especificidade conceitual apresentada por Schoenberg. Ela se baseia na recepção da obra de Webern, especialmente na América Latina. Em grande parte deve-se a Adorno a difusão da ideia de Klangfarbenmelodie, como se reconhece no Poetamenos, que não chegaria a Augusto sem a atuação de Hans-Joachim Koellreutter.

estruturas de origem e escrutinava e fazia escrutinar as transformaçōes destas ideias primeiras, a maneira em que eram suscetíveis de se desenvolver."

12 "Es ist nun möglich, aus Klangfarben, die sich der Höhe nach unterscheiden, Gebilde entstehen zu lassen, die wir Melodie nennen" (SCHOENBERG, 1922, p. 506). 
Koellreutter chega ao Brasil em 1937 e se torna o maior difusor da Segunda Escola de Viena ${ }^{13}$ no país, da técnica dodecafônica, e das obras de Schoenberg e Webern. Manuel Sosa (2009, p. 310) faz um histórico da recepção da obra de Webern na América do Sul, e, ao lado do trabalho de Koellreutter no Brasil, aborda o papel de Juan Carlos Paz, na Argentina, e de Rodolfo Holzmann, no Peru. Koellreutter, como compositor, flautista, professor, e criador do grupo "Música Viva" em 1939, influenciou toda uma geração de compositores e intérpretes brasileiros, entre os quais Guerra Peixe, Cláudio Santoro e Eunice Katunda. O "Música Viva” atuou intensamente na produção de concertos, formação de público e na difusão da música contemporânea brasileira até o ano de 1951, quando se desfez. Mas o trabalho de Koellreutter que teve maior repercussão está relacionado ao ensino de técnicas composicionais dodecafônicas e seriais, e difusão de compositores europeus que já utilizavam essas técnicas por, ao menos, duas décadas. Entre esses compositores destaca-se Webern, sobretudo pelo impacto que teve no Brasil.

Para Sosa (2009, p. 315, tradução nossa), a música de Webern influenciou outras artes na América do Sul durante o século XX: "a música de Webern foi o modelo para o universo poético ideal contido em um espaço musical" ${ }^{14}$ Mas deve-se observar que este "universo poético" foi criado em um contexto onde tais obras não foram tocadas. Ainda que Koellreutter pudesse propagar técnicas composicionais e mobilizar jovens compositores brasileiros na produção de suas obras, os concertos realizados pelo Música Viva, no que se refere a compositores europeus, apresentaram obras de Bach, Mozart e Schubert, por exemplo. Ou seja, obras de Webern, ou de Schoenberg não foram, nesse período, tocadas no Brasil, e o único contato com essas obras teria acontecido através de algumas poucas gravaçóes. Em seu trabalho sobre a Segunda Escola de Viena, na América do Sul, Fugellie $(2018)^{15}$ fornece uma lista completa de obras apresentadas em todos os concertos do grupo e faz uma comparação com outros países latino-americanos. Fica claro que a música dodecafônica tornou-se muito

$13 \mathrm{O}$ termo Segunda Escola de Viena refere-se aos compositores envolvidos no surgimento e desenvolvimento da técnica dodecafônica, e melodia de timbres. Ele é usado principalmente para destacar a relação entre as obras de Schoenberg e seus alunos, Webern e Berg. A Primeira Escola de Viena se estabeleceu mais de cem anos antes, com os compositores Haydn, Mozart e Beethoven.

14 "In the eyes of Young composers, his music and musical thinking were an intelectual/emotional foundation upon which they could build. Webern's music was the model for the ideal self-contained poetic universe of a musical space" (SOSA, 2009, p. 315).

15 Além das análises do livro de Fugellie (2018), as tabelas de concertos estão disponíveis em: https:// musikerunsererzeit.wordpress.com/tabellen/. Acesso em 28 mar. 2020. 
mais conhecida como uma ferramenta composicional do que como um movimento estético. Assim, um elevado grau de abstração em relação à sua experiência estética, e a seu contexto musical, envolve a recepção da obra de Webern no Brasil e na América Latina.

Em relação à recepção internacional da obra de Webern, Hiekel (2009, p. 323, tradução nossa) afirma, sobre a década de 1950, que há algum tempo ela já fazia parte de um currículo imaginário de composição europeia. ${ }^{16}$ Catherine Nolan (2009, p. 296, tradução nossa) concorda e afirma que a imagem que compositores faziam de Webern "foi cultivada a partir de uma mistura de fato e fantasia". ${ }^{17}$ Para Nolan, o conceito de modernismo, empregado em diversas áreas, desempenhou um importante papel na recepção da obra de Webern no pós-guerra - o compositor reconhecido como representante paradigmático do modernismo estético na música (NOLAN, 2009, p. 293-294). A autora também afirma que o "espírito do modernismo ativou a abstração de materiais musicais e formas de análise de Webern, e que elementos extramusicais têm sido parte dos estudos atuais sobre sua obra, fato raro antes das décadas de 1980 e 1990, devido ao formalismo associado ao modernismo na década de 1950" (NOLAN, 2009, p. 301, tradução nossa). ${ }^{18}$

Especialmente em relação aos compositores, e ainda sobre a recepção de Webern na década de 1950, Hiekel (2009, p. 318, tradução nossa) afirma que "a recepção da obra de Webern nesta década é considerada problemática hoje, porque ela estilizava Webern como um ídolo que servia à legitimação de seus próprios esforços em alcançar uma unidade construtiva". ${ }^{19}$ Notem que justamente esta "unidade", que se refere à criação de uma obra musical, foi mencionada por Schoenberg como um projeto futuro, especificamente em relação à "melodia de timbres". Para o autor, Webern foi considerado o arauto de uma nova ideologia composicional, que veio a ser chamada de serialismo, relacionada ao dodecafonismo, mas não ao dodecafonismo clássico, de Schoenberg. Os aspectos da música de Webern que inspiraram os compositores foram a abstração da linha musical, a atenção

16 "Im Prinzip kann wohl gelten, dass die Wiener Schule (und namentlich Webern) international längst zum imaginären Lehrplan des europaischen Kompositionsunterrichts zählt" (HIEKEL, 2009, p. 323).

17 "Their image of the composer [Webern] was cultivated from a mixture of fact and fantasy" (NOLAN, 2009, p. 296).

18 "The spirit of modernism certainly precipitated the abstraction of musical materials and designs in Webern analysis. A number of recent Webern scholars have allowed modernist criticism to stimulate their exploration of extra-musical considerations not manifest in Webern analysis before the 1980s and 1990s due to the formalism habitually associated with modernism since the 1950s" (NOLAN, 2009, p. 301).

19 "Die Webern-Rezeption der 1950er Jahre gilt heute als problematisch, da sie häufig Anton von Webern zum Idol stilisierte, das zur Legitimierung des eigenen Strebens nach konstruktiver Einheitlichkeit diente" (HIEKEL, 2009, p. 318). 
a duraçóes proporcionais e a permutação de elementos: "Eles também estavam extremamente interessados em aspectos espaciais de sua música, incluindo simetrias entre registros e simetrias temporais" (HIEKEL, 2009, p. 295-296, tradução nossa). ${ }^{20} \mathrm{~A}$ abstração da linha musical é criada pela fragmentação da melodia entre registros distintos (graves, médios e agudos). Para que cada fragmento seja ouvido independentemente, há o equilíbrio da duração de seus eventos em ritmos proporcionais, que, somados às alturas que formam melodias e harmonias, constituem elementos musicais compostos em permutação. $\mathrm{O}$ uso desses elementos, característicos da música serial, guarda o aspecto simétrico tanto das alturas, que definem registros distintos, quanto dos ritmos.

Os procedimentos que enfatizam notas isoladas, e pequenos grupos de intervalos, definem uma estrutura musical que caracteriza a melodia de timbres para o pianista. Eles também correspondem à opiniáo do próprio Augusto sobre a obra de Webern, em seu Música de Invenção (1998). Segundo o poeta, náo existem precedentes para a concisão formal e dialética som-silêncio apresentadas por Webern; o silêncio, audível pela primeira vez, não é meramente uma pausa, mas um elemento estrutural (CAMPOS, 1998, p. 96).

O ideal romântico, sugerido pelo pianista Gould (1953), ou as ideias de "ídolo" ou de "fantasia" relacionadas a Webern, e apresentadas respectivamente por Hiekel (2009) e Nolan (2009), podem ser estendidas para além de um domínio composicional, em relação à poesia de Augusto de Campos. Os aspectos espaciais e as simetrias mencionadas por Nolan (2009), que interessavam aos compositores seriais em relação à obra de Webern, também são representadas na espacializaçáo gráfica do Poetamenos. Mas a associação com o "novo" parece ter sido o aspecto mais decisivo para Augusto, o "poeta da recusa", com relação à Klangfarbenmelodie.

Webern representa uma escolha pelo novo. A opção pelo serialismo, de forma geral, em detrimento do dodecafonismo, como técnica composicional, evita de forma eficaz a "autoridade" de procedimentos composicionais que não observamos no Poetamenos (não há análogos das repetiçôes de ciclos de 12 elementos no Poetamenos). O "espaço de problemas" do poeta, de uma melodia de timbres, na esperança de transcriá-la com palavras, em muito se assemelha ao espaço criativo de compositores seriais, menos interessados num protocolo técnico do que em usá-lo como plataforma para novas e surpreendentes descobertas.

20 "They [serialist composers] were also greatly interested in spatial aspects of his music including registral and temporal symmetries" (HIEKEL, 2009, p. 296). 
Para Clüver (1981, p. 386, tradução nossa), a audição das obras de Webern tiveram "profundo impacto" sobre a criação do Poetamenos: "a experiência de ouvir as gravaçóes de obras selecionadas de Anton Webern por René Leibowitz, lançadas em 1950 em dois discos de vinil, teve profundo impacto na composição dos seis textos que marcam o começo da poesia concreta brasileira". ${ }^{21}$ Ele afirma que, em uma carta de 08 de junho de 1980 , Augusto lhe dissera que ele e Haroldo haviam comprado essas gravaçóes em 1952, e que elas continham o Concerto Op. 24, algumas cançōes, o Quarteto Op. 22, a Sinfonia Op. 21, e as Bagatelas Op. 9 etc. (CLÜVER, 1981, p. 397). Segundo Clüver, "uma composição que fascinou o poeta brasileiro de forma especial foi Quarteto Op. 22, de 1930" (CLÜVER, 1981, p. 389, tradução nossa), ${ }^{22}$ para violino, clarinete, sax tenor e piano, composto em técnica serial. Augusto teria afirmado, em 1973, que "lygia fingers' segue de forma praticamente literal a parte inicial do quarteto" (CLÜVER, 1981, p. 390, tradução nossa). ${ }^{23}$ Clüver (1981, p. 390-392) compara a cor de "elementos verbais" com a instrumentação de Webern. O nome lygia, em vermelho, na abertura do poema, corresponde à sequência de três notas do sax tenor (cp. 1), que é seguida pelo violino (cp. 2), que corresponde à cor verde de finge. A presença de duas cores em uma só palavra corresponde ao som simultâneo de sax e violino. Entretanto, não há aqui uma precisa correspondência entre a obra musical e o poema, já que a sequência musical, que ocorre no início do segundo compasso, deveria preceder, e não suceder, o finge rs ser, destacado por Clüver (1981, p. 392). A entrada do piano (ver partitura abaixo, Figura $4, \mathrm{cp} .3$ ) corresponde à cor violeta da palavra assim, novamente antecedida por interpolaçôes de cores que náo correspondem ao que encontramos na partitura, mas que corresponde aos métodos do compositor que, segundo Clüver (1981, p. 392), "se desenvolvem a partir do apelo a vários códigos semânticos e pelo processo de decompor e recombinar seus signos gráficos, resultando em um campo de diversas relações com a sintaxe espacial, que permite conexões horizontais, verticais e diagonais". ${ }^{24}$ Por fim, a entrada do clarinete (cp. 4) é representada pela cor amarela da palavra máe.

21 "Thus, the experience of listening to René Leibowitz' recording of selected Works by Anton Webern, published in 1950 on two Dial LP's, was to have a profound impact on the composition of the six texts which mark the beginning of Brazilian concrete poetry" (CLÜVER, 1981, p. 386).

22 "A composition which particularly fascinated the Brazilian poet was Webern's Quartet op. 22, of 1930" (CLÜVER, 1981, p. 389).

23 "lygia fingers' [...] follows almost literally the initial part of the quartet" (CLÜVER, 1981, p. 390).

24 "[Verbal motifs have been] developed by an appeal to several semantic codes and by a process of decomposing and recombining their graphic signs, resulting in a field of manifold relationships with a spacial syntax that allows for horizontal, vertical, and diagonal connections" (CLÜVER, 1981, p. 392). 


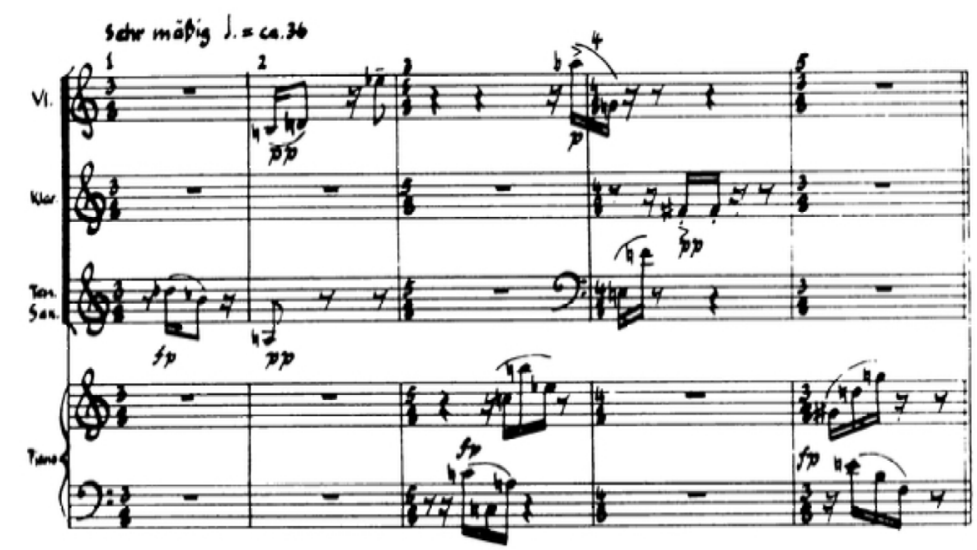

Figura 4 - Webern, Quarteto para Violino, Clarinete, Saxofone Tenor e Piano, Op. 22, primeiro movimento, compassos 1 a 5 .

Além de se referir apenas aos cinco primeiros compassos do Op. 22, que é um excerto extremamente curto e, portanto, pouco representativo, a correspondência entre instrumentos do quarteto e cores do poema está mais próxima do procedimento musical da instrumentação do que de uma melodia de timbres. Esta correspondência enfatiza a ordem de entrada de cada instrumento na composição, e não a elaboração timbrística dos instrumentos. No contexto da obra musical, a ampliaçáo da área de atuação das cores, como acontece na intercalação do vermelho e do verde, após as palavras lygia finge, que antecedem a entrada do piano, também parece incomum. Elas não correspondem a nenhum tipo de continuidade, polifonia, ou intervalo harmônico, efetuado pelos instrumentos propostos, sax tenor e violino. $\mathrm{Ou}$ seja, não se trata de uma transcriação direta da música de Webern para o poema, mesmo se considerarmos apenas seus cinco primeiros compassos.

Mas a música serial, como técnica composicional onde a "melodia de timbres" se desenvolve, possui diversas correspondências no Poetamenos. Procedimentos seriais, especialmente a justaposição de sequências de elementos musicais, como melodias e ritmos, foram parte da concepção de Augusto sobre a melodia de timbres. Qualquer investigação da música serial, e da melodia de timbres no contexto da música serial, ao abordar Poetamenos como uma transcriação, deve incluir: (1) a abstração da proposta de Schoenberg, ao preconizar uma "melodia de timbres"; (2) a intrincada discussão musicológica que se forma em torno da melodia de timbres, que hoje, depois de um século, pode ser considerada também histórica, com diferentes utilizações e sucessivas releituras; (3) a aplicação do mesmo termo a técnicas composicionais distintas; (4) diversas particularidades na recepção da melodia de timbres (e da música serial/dodecafônica) no Brasil e na América Latina. 
A música serial é uma técnica que pode ser realizada através de muitos elementos musicais, melódicos, rítmicos, dinâmicos etc. Ela consiste na criação de sequências, que podem ser compostas por notas, ritmos, dinâmicas, e devem ser repetidas na mesma ordem em que foram inicialmente apresentadas. Quando aplicada às doze notas musicais, chamada série dodecafônica, ela evita a polarização de uma tônica. Sequências musicais justapostas, independentemente do número de elementos, já que na música serial elas são mais curtas do que na técnica dos doze sons, estabelecem repetiçôes "invisíveis", porque permitem que alguns elementos ganhem variabilidade enquanto outros se repetem. Assim, as sequências evitam a repetição direta e literal de um tema, por exemplo, e também permitem coesão formal. No Poetamenos, os elementos (cores, espacialização gráfica, o uso de sílabas, palavras, frases) são tratados como sequências musicais (melódicas, rítmicas, dinâmicas etc.). Suas repetiçóes aparecem em componentes fônicos e na sintaxe, como em "dias dias dias" a palavra a mor na repetição em amemor, e reiterada no imperativo ame amor; ou a repetição de ex em expoeta expira, no mesmo poema. Esta reiteração de elementos fônicos, e também de cores e do espaçamento gráfico de sílabas e palavras, funciona como um mecanismo (musical) de coesão, como abordado por Schoenberg ao mencionar a "melodia de timbres", em que elementos musicais (harmonia ou melodia) fazem com que as obras soem como unidades, e sejam reconhecidas como tais.

Assim como as cores, as palavras e fragmentos (sílabas e letras), definidos pela espacialização gráfica, também funcionam como elementos de estruturação. Observando Webern, especialmente seu aspecto polifônico, a transcriação de uma melodia de timbres deveria incluir a interação de diversos elementos, e Augusto de Campos confirma essa tese em sua introdução à série. Mas a literatura secundária insiste em associar a Klangfarbenmelodie ao uso das cores no Poetamenos.

$\mathrm{Na}$ oralizaçáo dos poemas, mesmo quando lidos por diversos indivíduos, a distinção tímbrica das vozes não pode ser comparada a um coletivo instrumental, a exemplo de uma orquestra, onde dezenas de instrumentos diferentes produzem timbres também distintos. Grandes formaçōes instrumentais tendem a ser mais diversas, em termos tímbricos, pela simples variedade de fontes sonoras. Assim, uma transcriação da multiplicidade de timbres instrumentais, e consequentemente de melodias de timbres, não poderia equivaler a diversas vozes de leitura, mas à combinaçáo dos recursos semânticos, sintáticos e sonoros que essas vozes poderiam produzir. Isso aparece no Poetamenos em diversos níveis: (1) através de variaçóes semânticas e fônicas, como em digital e dedat; (2) em abreviaçôes e fragmentaçóes semânticas e fônicas, como so lange, sorella, so; (3) na repetição de letras e sílabas, como em ly, de lygia, lynx, felyna, only, lonely, tt, em digital e dedat, ou apenas 1; (4) no plurilinguismo, que sobrepóe sentidos aos "mesmos" signos verbais etc. 
Mantemos em foco o trecho do poema anteriormente analisado com relação às cores, e a polifonia verbal nas raízes semânticas de "lygia fingers". Numa primeira sequência, as associaçóes em torno de dedos (fingers/digital/ dedat) se relacionam com lygia e finge pela correspondência analógica entre letras e sons. Uma segunda sequência é formada pelas palavras lynx, felyna, figlia, felix, enquanto uma terceira une seja, ser, so lange, sorella. Se a primeira sequência é marcada pelas cores vermelho e verde, e a última pelas cores violeta e azul, a série central é formada por uma mistura dessas cores e pelo amarelo, que, no entanto, não destaca nenhuma palavra graficamente central à segunda sequência. Precisamente aí mostra-se a ação típica da sobreposição de sequências musicais distintas, por exemplo, melódicas e rítmicas. Ao mesmo tempo em que há diferenciação no material, a coesão formal é mantida pela própria repetição das sequências, assim como na segunda sequência de "lygia fingers", mencionada acima, onde modificamse os grupos de palavras, enquanto as cores são mantidas. Assim, o uso de sequências rítmicas, melódicas etc. torna-se um método para obter coesão formal, permitindo, ao mesmo tempo, variabilidade do material sonoro. Enquanto cores se repetem, e também letras, a exemplo do y de lygia, lynx e only, variaçôes e abreviaçôes semânticas e sonoras se multiplicam. A transformação entre as palavras fingers e ser, através dos fragmentos rs e $\mathbf{s r}$, também apresentam um procedimento serial muito típico, denominado retrógrado, que espelha uma melodia horizontalmente fazendo com que seu fim se torne seu início, nota por nota, começando pela última até a primeira. Há, em "lygia fingers", uma transcriação de "retrógrados musicais livres". ${ }^{25}$ O poema começa com o nome lygia e termina com a letra $\mathbf{l}$, com estruturas que se repetem, em cada letra do nome, em sentido inverso: a-i-g-y-l. O próprio poeta menciona a circularidade causada pela última letra do poema e a remete a um "da capo" musical (CAMPOS, 1978, p. 66-67). O exemplo não é um retrógrado exato, pois algumas letras se repetem mais vezes do que outras em sequências distintas à do nome próprio.

Finalmente, a combinação entre variações semânticas e cores resultaria em uma macro-estrutura que difere das três partes relacionadas às variaçóes semânticas. Antes, ela indica uma forma musical binária, A-B, onde se destacam as relações polifônicas entre as palavras assim seja, em violeta, e a última ocorrência do nome lygia, na vertical. A percepção de tal estrutura, ou o resultado da coesão dos elementos trabalhados, se baseia em uma leitura do poema que é polifônica. Mas, reiteramos, não se trata de muitas vozes, como seria em um coro-leitor, mas da combinação de variaçóes semânticas, sonoras e das cores.

25 Um retrógrado musical significa a repetição de uma sequência de notas em sua ordem inversa. Por exemplo: o retrógrado das notas Dó, Sol, Fá é composto pelas notas Fá, Sol, Dó. O serialismo aplicou o mesmo procedimento a ritmos, dinâmicas etc. A referência a retrógrados livres indica variaçôes sutis nas sequências, que náo impeçam o reconhecimento auditivo das mesmas como tais. 
O mesmo procedimento serial é observado na obra de Webern. No excerto apresentado (cinco primeiros compassos do Quarteto, Op. 22), sequências rítmicas e melódicas se intercalam. Enquanto nos dois primeiros compassos uma sequência de semicolcheia e duas colcheias separadas por uma pausa de semicolcheia se sucedem, nos compassos seguintes, ouvemse sequências de três e duas semicolcheias. A primeira sequência rítmica é associada a uma sequência melódica com os intervalos de terça e nona, resultando em vozes extremas que formam uma décima primeira. A repetição da mesma sequência melódica acontece um semitom acima, que é enfatizado pela proximidade das entradas das notas réb e sib na primeira ocorrência no sax tenor (ver partitura acima, Figura 4, cp. 1), seguidas por si e ré na segunda ocorrência tocada pelo violino (ver partitura acima, Figura 4, cp. 2). No final dessas sequências melódicas, as notas de destino variam, porque seguem movimentos contrários, descendente na primeira ocorrência e ascendente na segunda. Já na segunda das sequências rítmicas de três e duas semicolcheias, o intervalo de nona continua presente, assim como a segunda menor, na junção de frases entre instrumentos distintos, como se ouve no terceiro compasso o lá do piano e o lá, do violino. $\mathrm{O}$ jogo de movimentos contrários também é mantido, nas semicolcheias do piano, no violino e no sax tenor. A combinação entre alternância e manutenção de sequências, independente de sua natureza, fornece coesão formal à obra.

A coesão obtida por Webern, por meio da técnica serial, pode ser observada no Poetamenos. A série musical atua como unidade estruturante ${ }^{26}$ frente à fragmentação de seus elementos. Recordemos a resposta de Schoenberg a Webern sobre a melodia de timbres, como um elemento estruturador da obra. Para Schoenberg, a harmonia, os ritmos e melodias continuavam atuando como estruturas musicais, mais do que a própria melodia de timbres.

A extrema concisão das peças de Webern exerceram notável influência sobre Augusto. O poeta deve concordar com Adorno, para quem Webern teria chegado a uma nova forma de objetividade através do expressionismo em um sentido estrito (ADORNO, 1984, p. 448, tradução nossa) - "[Webern é] o único a propor o expressionismo musical em seu sentido mais estrito, levando-o a tal ponto que reverte seu próprio peso a uma nova objetividade" (ADORNO, 1984, p. 448). ${ }^{27}$ A concisão, em sequências rítmicas e melódicas, é uma propriedade weberniana que permite a coexistência da fragmentação do

26 Para Schoenberg (1975, p. 483), “Ao mesmo tempo em que a série musical cria variabilidade no uso de seus materiais, sua repetição atua como uma unidade estruturante. A ideia de unidade se relaciona à lógica de elementos musicais melódicos, rítmicos ou harmônicos, por exemplo. Em relação à melodia de timbres, a hipótese de Schoenberg era de que suas sequências correspondem à lógica interna de sequências harmônicas”.

27 "[Webern is] the only one to propound musical expressionism in its strictest sense, carrying it to such a point that it reverts of its own weight to a new objectivity" (ADORNO, 1984, p. 448). 
material e da coesão formal. Um bom exemplo dessa concisão (ou objetividade, segundo Adorno) na obra de Webern, são suas Seis Bagatelas para Quarteto de Cordas, de 1913, que duram aproximadamente três minutos no total. Allen Forte, que se dedicou ao estudo rigoroso dos intervalos e classes de notas na obra de Webern, enfatizou a unidade formal da obra, que permite que cada uma de suas Seis Bagatelas soem como singularidades: "O que é extraordinário sobre todas as composições do Opus 9 é que elas são tão individualizadas: cada uma parece apresentar sua própria ideia musical, que é composta da forma mais meticulosa possível" (FORTE, 1994, p. 174, tradução nossa) ${ }^{28}$ Curiosamente, as Seis Bagatelas correspondem, em número, aos seis poemas de Poetamenos, igualmente breves. A composiçáo era de conhecimento do poeta, já que uma interpretaçáo dela aparece no LP comprado por Augusto e Haroldo em 1952. Se nossa hipótese não está equivocada, a síntese do material musical weberniano, em sua concisão, fragmentação de elementos e coesão formal deve mais a Seis Bagatelas, do que ao Quarteto Op. 22, o papel de signo-fonte no processo de transcriação de Webern. Trata-se de uma refutação, portanto, do próprio autor, que declara uma influência maior do Quarteto Op. 22 sobre a série.

Augusto de Campos descreve a leitura do poema ${ }^{29} \mathrm{em}$ voz alta como "reverberação" - vozes reais como timbres, os instrumentos de Webern. Na leitura, a reverberação altera as relaçóes entre as palavras, que são destacadas, como a transformação de finge em fingers e finalmente em ser. Palavras que aparecem apenas uma vez são repetidas, com diferentes sentidos, como so lange (em alemão, so lange significa so long [ago], há tanto tempo) e o nome próprio Solange (ver nota 3), resultando em um terceiro sentido, em referência a acontecimentos passados. Pode-se afirmar, com relação à oralização de Poetamenos, que uma melodia de timbres, em um sentido estrito, resulta em um novo fenômeno, incluindo uma diferença entre polifonias vocais (vozes que leem) e instrumentais. A polifonia vocal está relacionada à enunciação de sílabas, palavras e sentenças, enquanto a polifonia instrumental é formada por melodias, o que as distingue fundamentalmente. Resulta, dessa distinçáo, uma prática performática da leitura, no sentido de uma performance musical do poema, que revela suas estruturas polifônicas - semânticas, sonoras, cromáticas etc. Essa performance acústica do poema não faz corresponder cores a vozes, mas se baseia na combinação de diversas sequências (semânticas, cromáticas etc.), como elementos de uma macroestrutura, que não existiria sem os silêncios que permitem suas subdivisôes.

28 "What is extraordinary about all the Opus 9 compositions is that they are so individualized: each one seems to present its own musical idea, which is composed out in the most meticulous way" (FORTE, 1994, p. 174).

29 Augusto de Campos lê "lygia fingers". Disponível em: https://www.youtube.com/watch?v=wx0XqXpQtO8 (Acesso em: 28 mar. 2020). 
O uso do silêncio, das pausas, como um material fundamental à estruturação do poema, é mais um aspecto musical que Augusto de Campos transcria de Webern, como vimos. O silêncio está associado ao uso e distribuição das sílabas, palavras, sentenças, pontuação e às cores, delimitando subdivisões de uma macroestrutura visual. Ao serem oralizados, os silêncios apresentam tanto as articulaçôes do sistema verbal, quanto o espaço gráfico necessário à associação entre elementos formantes da obra, a separação de sílabas, que se lê repetidamente na sílaba ly de "lygia fingers". Segundo Augusto de Campos, este procedimento torna o silêncio "audível" podendo ser equiparado ao som (CAMPOS, 1998, p. 96), e contribui para uma caracterização da obra de Webern como de uma concisão formal "sem precedentes" (CAMPOS, 1998, p. 96).

Existem diferentes formas de silêncio no Poetamenos. Algumas estáo relacionadas ao espaço gráfico, em branco na página impressa, as pausas entre as frases musicais. Esta é a forma mais notável de correlação, e é a mais mencionada. O espaço gráfico está diretamente relacionado a uma percepçáo da macroestrutura dos poemas, como as duas seçóes com ênfase nas cores primárias em "lygia fingers", e a seção intermediária com combinaçôes dessas cores. ${ }^{30}$

As cores das palavras, sílabas e letras são "instrumentos", como Augusto afirma na introdução aos poemas (Figura 1). Os timbres desses instrumentos são definidos por um tema "gráfico-fonético" ou "ideograma". Os temas (ideogramas), por sua vez, são as "séries" (musicais) a partir das quais se realiza a "melodia de timbres". Elas dependem, como na música de Webern, da relação entre todos os elementos espaciais, sonoros e semânticos que constituem o poema.

\section{Conclusão}

A Klangfarbenmelodie surgiu como uma projeção, não como uma técnica estrita, na obra de Schoenberg, uma "fantasia do futuro" (SCHOENBERG, 1922 , p. 507). Esta projeção é retomada no domínio da poesia. Qualquer discussão sobre seu desenvolvimento deve incluir contribuiçôes musicológicas e históricas, porque é impossível tratá-la de forma inequívoca, relacionada a um compositor específico, ao próprio Schoenberg, a Webern, ou a qualquer outro compositor, sem excursos musicológicos. É necessário compreender a Klangfarbenmelodie em termos contextuais. Sua replicação como técnica, especialmente quando relacionada à obra de Webern, não pode ser feita.

30 Os silêncios também são criados pelo uso surpreendente dos parênteses em outros poemas da série "semen (t)emventre", em "eis os amantes"; o espaçamento entre as letras — " $\mathrm{t}$ " e a "té $\mathrm{t}$ ", em "nossos dias com cimento"; o uso de apóstrofos - "exampl'eu", em "paraíso pudendo"; a separaçáo silábica — "ab rupt", e o uso dos dois pontos, por suposto:, em "poetamenos". Os silêncios também são subtraídos, ou comprimidos, em fusóes - "aquelele", em "eis os amantes". 
No entanto, a literatura secundária sobre o Poetamenos descreve o uso das cores como a realização de uma Klangfarbenmelodie, relacionada à obra de Webern, sem qualquer discussão musicológica detalhada sobre sua realização. Klangfarbenmelodie aparece, nessa literatura, como uma técnica, não como um fenômeno complexo com diversas e divergentes implicaçóes terminológicas, históricas e conceituais.

O próprio Augusto de Campos indica, na introdução aos poemas, que não são apenas as cores que definem uma Klangfarbenmelodie, mas um "ideograma" formado por "frase/palavra/sílaba/letra(s), cujos timbres se definem por um tema gráfico-fonético ou 'ideogrâmico"” (1973, introdução). Essa "combinação de elementos" transcria a função de séries melódicas, rítmicas etc. que, na obra de Schoenberg, e de seus alunos, define a "música serial" (ou serialismo), técnica composicional cujos procedimentos podem ser replicados, como foram por muitos compositores.

Em nossa argumentação, a técnica serial exerceu o papel de signofonte na transcriação de Augusto. Poetamenos é um ícone do serialismo de Webern. Também sugerimos que a coesão e concisão webernianas estão entre as propriedades mais importantes na transcriaçâo. Ele transcria a técnica serial weberniana, através de um pequeno acervo lexical, fragmentação deste acervo, concisão e coesão criadas pela justaposição associativa e acumulativa dos fragmentos. Mais radicalmente, Poetamenos transcria a técnica que cria a dialética "som versus silêncio", "coesão formal (cf. Augusto de Campos, "sem precedentes") versus fragmentaçáo", e revela, reinventando-os intersemioticamente, os protocolos e os efeitos históricos criados pela técnica. Algumas das propriedades transcriadas do serialismo weberniano, que inspiraram muitos compositores contemporâneos, foram a abstraçáo da linha musical, a fragmentaçáo da melodia entre registros graves, médios e agudos, a atenção a duraçóes proporcionais e a permutaçáo de elementos, além de simetrias temporais.

Poetamenos encontrou no serialismo (mais do que na literatura, e mesmo nas artes visuais), no rigor formal exibido pela técnica, o desenvolvimento de uma "linha evolutiva" formal preconizada pelo grupo "Noigandres" para definir o fim do ciclo histórico do verso. Pode-se afirmar que o Poetamenos é uma transcriação pré-concretista da coesão e concisão formais, e dialética som-silêncio (silêncio audível como elemento estrutural) sem precedentes históricos, descoberto pelo Webern de Augusto, através da interpretação de Adorno, via Koellreutter; ou, o Webern que interessava aos propósitos concretos de Augusto, através de Adorno, via Koellreutter. Ele baseia-se numa interpretação adorniana da fragmentação da sequência melódica, cuja correspondência intersemiótica conduz, "numa dialética da necessidade e uso históricos" (PIGNATARI, 1956), ao "fim do ciclo histórico do verso". 
ADORNO, Theodor. Musikalische Schriften. Berlin: Suhrkamp Verlag, 1984.

ADORNO, Theodor. Anton Webern: zur Aufführung der fünf Orchesterstücke in Zürich. In: HEINSHEIMER, Hans; STEFAN, Paul (Orgs.). Musikblätter des Anbruch, v. 8, Wien: Universal Edition, 1926. p. 280-282.

AGUILAR, Gonzalo. Poesia concreta brasileira: as vanguardas na encruzilhada modernista. São Paulo: Edusp, 2005.

AGUILAR, Gonzalo; CÁMARA, Mario. A máquina performática: a literatura no campo experimental. Rio de Janeiro: Rocco, 2017.

BESSA, Antonio Sergio. Sound as subject: Augusto de Campos Poetamenos. In: PERLOFF, Marjorie; DWORKIN, Craig (Orgs.). The sound of poetry. The poetry of sound. Chicago: University of Chicago Press, 2009. p. 219-236.

BENJAMIN, Walter. The task of the translator: an introduction to the translation of Baudelaire's. In: ARENDT, Hannah (Org.). Walter Benjamin: illuminations. London: Fontana/Collins, 1973 [1923]. p. 69-82.

CAMARA, Rogério. Grafo-sintaxe concreta: o projeto Noigandres. Rio de Janeiro: Rios Ambiciosos, 2000.

CAMPOS, Augusto. Mallarmé, 4. ed. Sáo Paulo: Editora Perspectiva, 2015.

CAMPOS, Augusto. Música de Invenção. São Paulo: Perspectiva, 1998.

CAMPOS, Augusto. Poesia, antipoesia, antropofagia. São Paulo: Companhia das letras, 1978.

CAMPOS, Augusto. Poetamenos. São Paulo: Ediçóes Invenção, 1973 [1953].

CAMPOS, Haroldo. Metalinguagem \& outras metas. São Paulo: Perspectiva, 2004 [1972].

CAMPOS, Haroldo. O Arco-íris branco. São Paulo: Imago, 1997.

CAMPOS, Haroldo. Da tradução como criação e como crítica. In: TÁPIA, Marcelo; NÓBREGA, Thelma Medici (Orgs.). Haroldo de Campos: transcriação. São Paulo: Perspectiva, 2013. p. 01-18.

CARVALHO, Audrei Aparecida Franco. Poesia concreta e mídia digital: o caso Augusto de Campos. Dissertação (Mestrado em Comunicação e Semiótica). Pontifícia Universidade Católica de São Paulo, São Paulo, 2007.

CLÜVER, Claus. From imagism to concrete poetry: breakthrough or Blind Alley? In: HAAS, Rudolf (Org.). Amerikanische Lyrik: perspektiven und interpretationen. Berlin: Erich Schmidt, 1987. p. 113-30. 
CLÜVER, Claus. Klangfarbenmelodie in polychromatic poems: Anton von Webern and Augusto de Campos. Comparative Literary Studies, v. 18, p. 386-398, 1981.

DUSI, Nicola. Translating, Adapting, Transposing. Applied Semiotics. On translation and Intersemiotic translation, v. 9, n. 24, p. 82-94, 2010.

ECO, Umberto. Quase a mesma coisa. Rio de Janeiro: Record, 2007.

EGGEBRECHT, Hans Heinrich. Terminologie der Musik im 20. Jahrhundert Stuttgart: Franz Steiner Verlag, 1995.

FABRI, Albrecht. Preliminares a uma teoria da literatura [Präliminarien zu einer Theorie der Literatur]. Augenblick: Stuttgart-Darmstadt, n. 1, 1958.

FORTE, Allen. An Octatonic Essay by Webern: No.1 of the Six Bagatelles for String Quartet, Op. 9. Music Theory Spectrum, v. 16, n. 2, p. 171-195, 1994.

FUGELLIE, Daniela. Musiker unserer Zeit: internationale avantgarde, migration und wiener schule in südamerika. München: Edition Text+Kritik, 2018.

FUGELLIE, Daniela. Tabelas de concertos do grupo Música Viva. [s.l.]. [s.n.]. 2018. Disponível em: https://musikerunsererzeit.wordpress.com/tabellen/. Acesso em 28 mar. 2020.

GOULD, Glenn. Program for the New Music Associates Concert. [s.l.]. [s.n.]. 1953. Disponível em: https://www.uv.es/ calaforr/Webern/gould.htm. Acesso em 28 mar. 2020.

GORLÉE, Dinda. Jakobson and Peirce: Translational intersemiosis and symbiosis in opera. Sign Systems Studies, vol. 36, n. 2, p. 341-373, 2008.

GORLÉE, Dinda. Singing on the breath of God. In: GORLÉE, Dinda (Org.). Song and significance: virtues and vices of vocal translation. Amsterdam/New York: Rodopi, 2005. p. 17-101.

GORLÉE, Dinda. Intercode translation: Words and music in opera. Target 9, v. 2, p. 235-270, 1997.

GORLÉE, Dinda. Semiotics and the problem of translation with special reference to the semiotics of Charles S. Peirce. Amsterdam/Atlanta: Rodopi, 1994.

HIEKEL, Jörn Peter. Der veränderte Blick: zur Situation der Webern-rezeption heute. In: SCHWEIGER, Dominik; URBANEK, Nikolaus (Orgs.). Webern 21. Wien: Böhlau Verlag, 2009. p. 319-333.

HOOKWAY, Christopher. Truth, rationality and pragmatism: themes from Peirce. Oxford: Oxford University Press, 2002. 
JAKOBSON, Roman. On linguistic aspects of translation. In: VENUTI, Lawrence (Org.). The Translation Studies Reader. London/New York: Routledge, 2000 [1959]. p. 113-118.

JAKOBSON, Roman. Poetry of grammar and grammar of poetry: (Excerpts). Poetics Today, v. 2, p. 83-85, 1980.

NOLAN, Catherine. The modernist ethos in post-1945 Webern analysis. In: SCHWEIGER, Dominik; URBANEK, Nikolaus (Orgs.). Webern 21. Wien: Böhlau Verlag, 2009. p. 293-301.

PEIRCE, Charles S. 1931-1935. The Collected Papers of Charles Sanders Peirce. Vols. I-VI [C. Hartshorne, and P. Weiss, eds. Cambridge: Harvard University Press, 1931-1935]; Vols. VII-VIII [A. W. Burks (ed.), same publisher, 1958]. (Citado como CP).

SCHOENBERG, Arnold. Style and Idea. New York: St. Martins Press, 1975.

SCHOENBERG, Arnold. Harmonielehre. Wien: Universal Edition, 1922.

SCHMUSCH, Rainer. Klangfarbenmelodie. In: EGGEBRECHT, Hans Heinrich (Org.). Terminologie der Musik im 20. Jahrbundert Stuttgart: Franz Steiner Verlag, 1995. p. 221-234.

SOSA, Manuel. From Argentina to Venezuela: a historical overview of the impact of Anton Webern's music in South America. In: SCHWEIGER, Dominik; URBANEK, Nikolaus (Orgs.). Webern 21. Wien: Böhlau Verlag, 2009. p. 303-317.

TOROP, Peter. Intersemiosis y traducción intersemiótica. Cuicuilco, v. 9, n. 25, p. 1-30, 2002.

\section{Partituras}

WEBERN, Anton. Cinco Movimentos para Quarteto de Cordas. Op. 5. Viena: Universal Editions, 1922. Partitura.

WEBERN, Anton. Concerto. Op. 24. Viena: Universal Editions, 1948. Partitura.

WEBERN, Anton. Quarteto para Violino, Clarineta, Saxofone Tenor e Piano. Op. 22. Viena: Universal Editions, 1932. Partitura.

WEBERN, Anton. Seis Bagatelas para Quarteto de Cordas. Op. 9. Viena: Universal Editions, 1924. Partitura.

WEBERN, Anton. Sinfonia. Op. 21. Viena: Universal Editions, 1929. Partitura. 


\section{Gravações}

SYMPHONY: opus 21. Anton Webern (compositor). René Leibowitz (Regente). Estados Unidos: Dial Records, 1950. [LP].

Joáo Queiroz. Professor do Instituto de Artes da Universidade Federal de Juiz de Fora, Minas Gerais, e do Programa de Pós-Graduaçáo em Comunicação da mesma instituição, onde coordena o Grupo de Pesquisa Iconicity Research Group (IRG). Ele tem ministrado cursos de Semiótica Cognitiva, Filosofia da Arte, Estudos de Intermidialidade e supervisionado projetos nas áreas de Semiótica, Arte e Literatura Latino-Americana e Estética. Tem várias publicações em jornais (nacionais e internacionais), livros e enciclopédias. Queiroz é membro do International Association for Cognitive Semiotics (IACS), do Grupo de Pesquisa em Cognição Artificial (UEFS, Brasil), e pesquisador associado ao Linguistics and Language Practice Department, University of the Free State (África do Sul).

E-mail: queirozj@gmail.com

Ana Luiza Fernandes. Doutoranda em Literatura Comparada pela Pontifícia Universidade Católica do Rio de Janeiro, Brasil. É pesquisadora associada do grupo Iconicity Research Group (IRG). Seus temas de pesquisa incluem: design gráfico, intermidialidade, estudos interartes, fotolivro, fotolivro de literatura, semiótica.

E-mail: analuizadagama@gmail.com

Marta Castello-Branco. Professora do Departamento de Música do Instituto de Artes da Universidade Federal de Juiz de Fora, Minas Gerais, e do Programa de Pós-Graduação em Artes, Cultura e Letras da mesma instituição. Concluiu seu doutorado na Universität der Künste (UdK), Berlin, sobre a relação entre a filosofia de novas mídias, de Vilém Flusser, e a música contemporânea (2014). Entre suas principais publicações estão os livros: Reflexóes sobre Música e Técnica (UFBA, 2012), O Instrumento Musical como Aparelho (UFJF, 2015), a organização, tradução e apresentação do livro Na Música. Vilém Flusser (Annablume, 2017). Em 2018, fez pós-doutorado no Instituto Aryamarga, na Índia. Seus tópicos de pesquisa incluem: relação entre música, cultura e sociedade, estudos da relação entre técnica, materialidade e expressão musical, universalismo e essencialismo na música.

E-mail: martacastellobranco@yahoo.com.br 